\title{
Carabid beetles in a regional and a country-wide elevation gradient of Bavarian forests: differences and thoughts on the value of false time series approaches
}

\author{
Stefan Müller-Kroehling ${ }^{\ddagger}$, Matthias Jantsch ${ }^{\S}$ \\ ‡ Bavarian LWF, Freising, Germany \\ $\S$ TUM (formerly), Freising, Germany
}

Corresponding author: Stefan Müller-Kroehling (stefan.mueller-kroehling@lwf.bayern.de)

Received: 17 Jun 2019 | Published: 18 Jun 2019

Citation: Müller-Kroehling S, Jantsch M (2019) Carabid beetles in a regional and a country-wide elevation gradient of Bavarian forests: differences and thoughts on the value of false time series approaches. ARPHA Conference Abstracts 2: e37427. https://doi.org/10.3897/aca.2.e37427

\begin{abstract}
We studied the effects of global warming and rising temperatures on the ground beetle fauna of Bavarian beech forests using the space for time approach (false time series), and did so in two projects, at two geographical scales: firstly, a Bavarian-wide gradient of 50 plots in beech forests, and second a regional gradient in the Bavarian Forest in the mountains in eastern Bavaria consisting of 48 plots, which was not restricted to beech forests but also included subalpine spruce forests. For purposes of validation, we used as a backdrop data from 413 additional plots all across Bavaria from a wide range of forest habitats.

We found five species that would be favoured and six species that would be disadvantaged by rising temperatures in beech forests. For another five species the conditions within the gradient studied reach both their minimum and their maximum temperatures. As a consequence of increasing temperatures there will be winners and losers in these forests and the species composition of ground beetle communities will change. Approximately the
\end{abstract}


same number of species is likely to profit as will be affected negatively. However, when considering the "global responsibility species" for Germany, the balance is negative.

It is imporant to note that species may react differently in different habitats and at different regional scales. Some species migtht be more endangered in a local gradient than in a regional gradient, and vice versa, and examples are provided for this. Climate effects proven for a certain habitat must not be the same for other habitats even within the same region if these were not included in the study design. These limitations must be taken into consideration when applying the results of such studies and especially when generalizing them.

The benefits of a true time series compared to the popular "false time serices" provided by an elevational gradient are also highlighted using some examples.

\section{Keywords}

Carabidae, climate change, elevational gradient, false time series, true time series, beech forests, spruce forests.

\section{Presenting author}

Dr. Stefan Müller-Kroehling

\section{Presented at}

19thECM oral communication 